\title{
$\mathrm{M}|\mathrm{R}| \mathrm{S}$ Internet Journal Nitride Semiconductor Research
}

\section{Preparation of Sapphire for High Quality III-Nitride Growth}

\author{
J. Cui ${ }^{1}$, A. Sun ${ }^{1}$, M. Reshichkov ${ }^{1}$, F. Yun ${ }^{1}$, A. Baski ${ }^{1}$ and H. Morkoç ${ }^{1}$ \\ ${ }^{I}$ Virginia Commonwealth University,Department of Electrical Engineering and Physics Department,
}

(Received Friday, June 2, 2000; accepted Friday, July 21, 2000)

\begin{abstract}
We developed a unique preparation technique to eliminate surface damage on the c-plane of sapphire and render it atomically flat. AFM images of c-plane sapphire annealed at $1380{ }^{\circ} \mathrm{C}$ for 1hour show terrace-like features with about $0.2 \mu \mathrm{m}$ long terraces. The GaN layers grown by $\mathrm{MBE}$ on annealed sapphire have [l $\left.\begin{array}{lll}0 & 0 & 2\end{array}\right]$ symmetric and [llll 104$]$ asymmetric full width at half maximum (FWHM) of about 60 and 132 arcsec, respectively. This compares with 408 and 600 arcsec, respectively, for $\mathrm{GaN}$ grown on sapphire having gone through conventional chemical cleaning.
\end{abstract}

\section{Introduction}

In recent years the III-V nitrides have attracted much attention [1] because of the potential to produce hightemperature and high-power electronic devices [2], as well as bright blue light-emitting diodes (LEDs) [3], lasers [4] and solar blind UV photovoltaic detectors [5]. [a] Motivations for GaN based high-temperature, high-power electronics are due to GaN's high electronsaturation velocity, wide bandgap, high thermal conductivity and the availability of heterojunctions. Essential in exploiting all these applications is high-quality III-V nitrides.

One of the bottlenecks that have hindered the development of $\mathrm{GaN}$ is the lack of a suitable substrate material that is lattice matched to and thermally compatible with GaN. Due to the lack of an ideal substrate, nearly all III-V nitride materials are grown on sapphire despite its poor structural and thermal match to III-Nitrides. The predilection towards sapphire substrates is due to its availability, low cost, and its ease of handling and improving quality. Sapphire is also stable at high temperatures (about $1000^{\circ} \mathrm{C}$ ), a property that is required for epitaxial growth using the various deposition techniques commonly employed for $\mathrm{GaN}$ [7], [8]. In addition, its transparence to visible light makes it ideal for some detector application. The most commonly used orientation of sapphire for GaN, AlN and InN growth is the (0001) orientated basal plane, but the $(21(-3) 1),(110 \overline{1})$, (1120) planes have also been explored. A mechanicalchemical-polish involving many process steps is employed by sapphire manufacturers which produces a reasonable overall flatness of the surface, but leaves excessive damage and visible scratches caused by the grit used.

It has been established that the crystal structure of epitaxial $\mathrm{GaN}$ is strongly influenced by not only the substrate material and its orientation, but to a great extent the surface preparation of the substrate. An ideal cplane sapphire surface for epitaxy would have bi-layer steps leading to the realm where all the terrace surfaces have the same surface polarity so that stacking mismatch boundaries as well as other defects in the ensuing nitride deposition can be avoided. Therefore, in addition to a clean and damage-free surface, an atomically flat surface is imperative for 2D growth. As alluded to earlier, the surface of as-received sapphire is not acceptable for high quality epitaxial growth due, in part, to damage during polishing as a result of its hardness. While chemical etching and/or plasma etching can remove some of the damage, the resultant surface morphology is not ideal, as these etches attack the damaged regions faster [1].

A substrate surface can be likened to the foundation of a building; as such, substrate preparation [9] deserves the most attention. In this article, we report on a unique preparation technique to remedy the aforementioned shortcomings associated with the c-plane sapphire surface and render it atomically smooth. A comparison between the GaN layers grown by MBE on sapphire having undergone conventional preparation and the preparation method under discussion is also given.

\section{Experimental details}

The details of the procedure employed are as follows: Sapphire substrates first undergo a chemical (solvent) 
cleaning procedure [10], in which the substrate is dipped in a solution of TriChloroEthylene (TCE) for 5 minutes. The substrate is then rinsed for 3 minutes each in acetone and methanol. This procedure is followed by a 3-minute rinse in deionized (DI) water. The above steps are repeated three times to complete the degreasing process.

Following the degreasing procedure, the surface damage is removed by chemical etching. A 3:1 solution of hot $\mathrm{H}_{2} \mathrm{SO}_{4}: \mathrm{H}_{3} \mathrm{PO}_{4}\left(300{ }^{\circ} \mathrm{C}\right)$ is then used for $20 \mathrm{~min}$ utes to remove some of the surface material. This is followed by a rinse in DI water for 5 minutes. As will be discussed, this procedure serves to remove the surface damage but does not lead to smooth surfaces. Following this procedure, sapphire substrates (2-inch whole wafers) were subjected to a high temperature heat-treatment (in a resistively heated furnace) in air, which will be discussed in detail in the next section. Before put the sapphire into the chamber for epitaxy, it is rinsed for 3 minutes each in acetone and methanol. Followed by a 3minute rinse in deionized (DI) water.

Sapphire substrates as well as the GaN layers grown on them were characterized by AFM (Digital Nanoscan III), and X-ray diffraction (Philips MRD with 10 are second resolution). The MBE growth on the sapphires was performed in an SVT system using radio frequency (RF) plasma as well as in a Riber system using $\mathrm{NH}_{3}$.

\section{Results}

Shown in Figure 1 are AFM images of two c-plane sapphire surfaces, (a) before and (b) after the chemical etching. It is very clear that the etching did not remove the scratches from the surface that was introduced during the polishing process. Obviously, smoothness at the atomic level is not seen even though the root-meansquare (RMS) roughness was reduced from $0.32 \mathrm{~nm}$ in image (a) to $0.21 \mathrm{~nm}$ in image (b).

Figure 2 shows AFM images after annealing of sapphire for 30 minutes at (a) $1100^{\circ} \mathrm{C}$; (b) $1200{ }^{\circ} \mathrm{C}$; (c) $1300{ }^{\circ} \mathrm{C}$; and (d) $1380{ }^{\circ} \mathrm{C}$. Damage lines were reduced greatly although the atomically smooth surface did not emerge. In fact the RMS of the images increased from $0.22 \mathrm{~nm}$ for image (a) up to $0.49 \mathrm{~nm}$ for image (d). On occasion large dots appeared on the surface, as shown in (b) or many tiny dots as shown in (c).

In our quest to obtain atomically smooth surfaces, anneal time was increased to 1 hour or longer. Figure 3 (a) represents the surface annealed at $1000^{\circ} \mathrm{C}$ for 1 hour while that in (b) represents the one annealed at $1300{ }^{\circ} \mathrm{C}$ for 1 hour. As one can see, the surface changed into a smooth one and the terrace structure began to appear albeit randomly. The RMS reduced from 0.29 for image (a) to 0.14 for image (b). As shown in Fig. (c), when the substrate was annealed at $1380{ }^{\circ} \mathrm{C}$ for 1 hour, however, an atomically flat surface became clearly visible as judged by the straight and uniform terrace structure. The RMS roughness value for this image is only $0.07 \mathrm{~nm}$. The diagonal lines from left to right are the artifacts of AFM. When the anneal time was extended to 3 hours at $1380{ }^{\circ} \mathrm{C}$, as shown in (d), the surface roughened somewhat as the RMS roughness value increased to 0.14 . The steps and the terraces assumed a zigzagged and random distribution.

Sapphire substrates subjected to this proper high temperature heat treatment exhibits very smooth morphology. Shown in Figure 4 is an AFM image showing terrace-like features with about $0.2 \mu \mathrm{m}$ long terraces. The terrace structure could facilitate smooth 2D growth and reduce column formation during the growth of $\mathrm{GaN}$ epilayers other than those caused by the lattice mismatch. To ascertain the effect of the process under discussion on epitaxial GaN, MBE of GaN on the annealed and unannealed sapphire has been performed. The details and the specifics of the layered structures used in the MBE will be reported at a later date [11]. Table 1 lists the X-ray rocking curve results, which clearly indicate that the crystal properties have been improved substantially on annealed sapphire. The sample SVT 319 is a GaN layer grown by RF MBE on unannealed sapphire (the sapphire surface morphology is shown in Figure 1 (b)), while SVT 389 is a GaN layer grown on sapphire that was annealed at $1380{ }^{\circ} \mathrm{C}$ for 1 hour (the morphology is shown in Figure 4). The sample R6385 is a GaN layer grown by $\mathrm{NH}_{3} \mathrm{MBE}$ on the same annealed sapphire. The GaN layers grown by MBE on annealed sapphire have [ [ $\left.\begin{array}{lll}0 & 0 & 2\end{array}\right]$ symmetric and [ 1004$]$ asymmetric full width at half maximum (FWHM) of as low as 60 and 132 arcsec (sample R6385), respectively. These figures compare with 408 and 600 arcsec (sample SVT 319), respectively, for GaN grown on sapphire which did not undergo the high temperature annealing process. It should be emphasized that the X-ray results for the growth on sapphires annealed at other temperatures or for other anneal times were not as good as those on that were annealed at $1380{ }^{\circ} \mathrm{C}$ for 1 hour. The average X-ray data over some $20 \mathrm{GaN}$ samples are about 180 for [0 0 2] and 300 arcsec for [ $\left[\begin{array}{lll}1 & 0 & 4\end{array}\right]$, respectively. In other words, the $1380{ }^{\circ} \mathrm{C}$ for 1 -hour annealing procedure appears to represent the best heat-treatment conditions of sapphire for GaN epitaxy.

\section{Conclusions}

Atomically flat c-plane sapphire surfaces have been obtained through an annealing process in air at $1380{ }^{\circ} \mathrm{C}$ for 1 hour. AFM images show terrace-like features with about $0.2 \mu \mathrm{m}$ long terraces with bi-layer steps. The GaN layers grown by MBE on annealed sapphire exhibited 


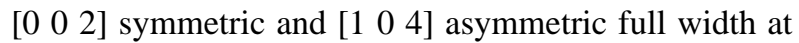
half maximum (FWHM) as low as 60 and 132 arcsec, respectively. This compares with 408 and 600 arcsec for

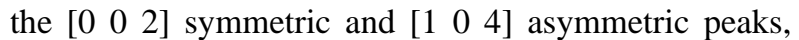
respectively, for GaN grown on standard sapphire.

\section{ACKNOWLEDGMENTS}

This work has been funded by grants from ONR (Drs. C. E. C. Wood and Y. S. Park -monitors), AFOSR (Dr. G. L. Witt - monitor) and NSF (Drs. V. Hess and G. Pomrenke - monitors). The authors would like to express their sincere appreciation of the hard work and dedication of Mr. T. King. J. Cui would like to thank Mr. K. M. Jones and Mr. M. Redmond for careful reading of the manuscript.

\section{REFERENCES}

[a] for a recent review, see [6].

[1] H. Morkoç: "Nitride Semiconductors and Devices", Springer, ISBN 3-540-64038-x, (1999)

[2] M. Asif Khan, A. Bhattarai, J. N. Kuznia, D. T. Olson, Appl. Phys. Lett. 63, 1214-1215 (1993).

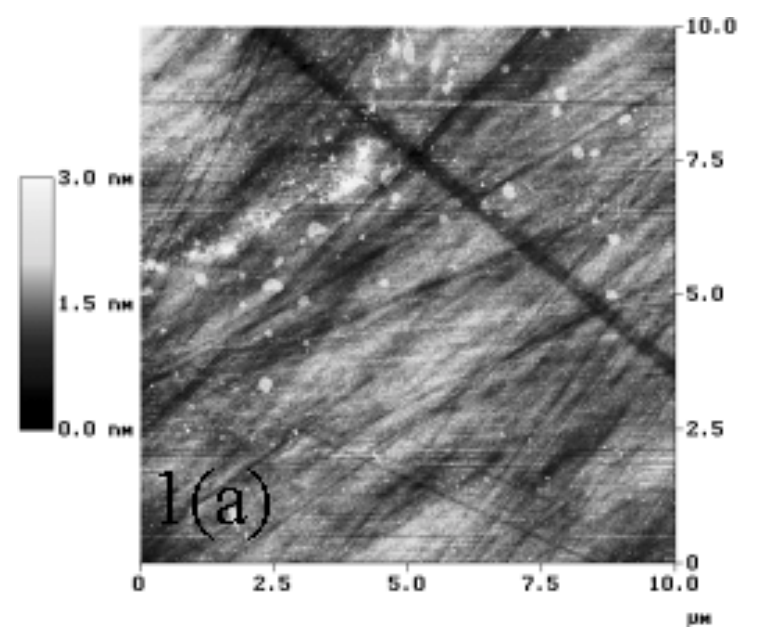

[3] S. Nakamura, T. Mukai, M. Senoh, J. Appl. Phys. 76, 8189 (1994).

[4] S. Nakamura, M. Senoh, S. Nagahama, N. Iwasa, T. Yamada, T. Matsushita, H. Kiyoku, Y. Sugimoto, Jpn. J. Appl. Phys. 35, L217-L220 (1996).

[5] G. Y. Xu, A. Salvador, W. Kim, Z. Fan, C. Lu, H. Tang, H. Morkoc, G. Smith, M. Estes, B. Goldberg, W. Yank, S. Krishnankutty:, Appl. Phys. Lett. 71, 2154 (1997).

[6] Hadis Morkoç, Aldo Di Carlo and R. Cingolani, "GaNBased Modulation Doped FETs and UV Detectors", Condensed Matter News, Ed. Patrick Bernier, in press

[7] S. N. Mohammad, H. Morkoç, Prog. Quantum Electron. PQE20, 361-525 (1996).

[8] H. Morkoc, S. Strite, G. B. Gao, M. E. Lin, B. Sverdlov, M. Burns , J. Appl. Phys. 76, 1363-1398 (1994).

[9] M. Seelmann-Eggebert, H. Zimmermann, H. Obloh, R. Niebuhr, B. Wachtendorf, Mater. Res. Soc. Symp. Proc. 468, 193 (1997).

[10] A. Botchkarev, A. Salvador, B. Sverdlov, J. Myoung, H. Morkoc, J. Appl. Phys. 77, 4455-4458 (1995).

[11] H. Morkoç, unpublished

\section{FIGURES}

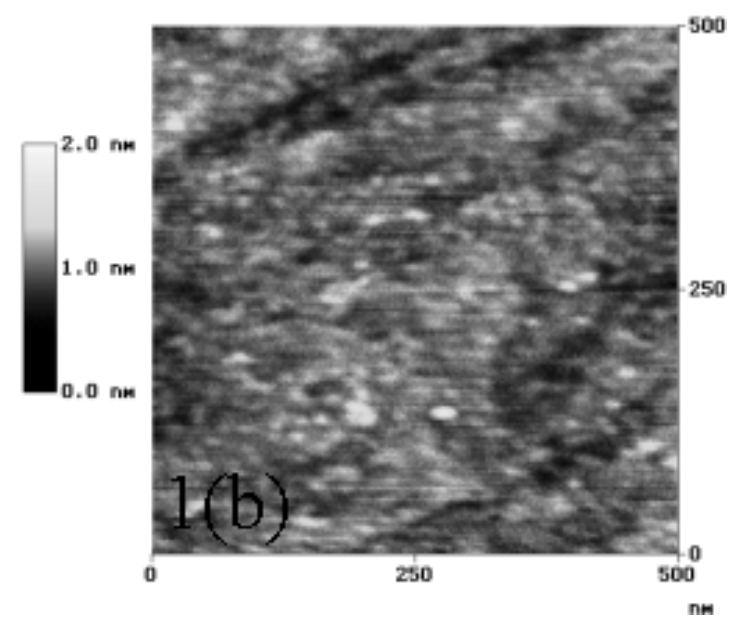

Figure 1. AFM images of sapphire surface (a) before etching, and (b) after etching in hot $\mathrm{H}_{2} \mathrm{SO}_{4}: \mathrm{H}_{3} \mathrm{PO}_{4}$ at $300{ }^{\circ} \mathrm{C}$ for 20 minutes. 

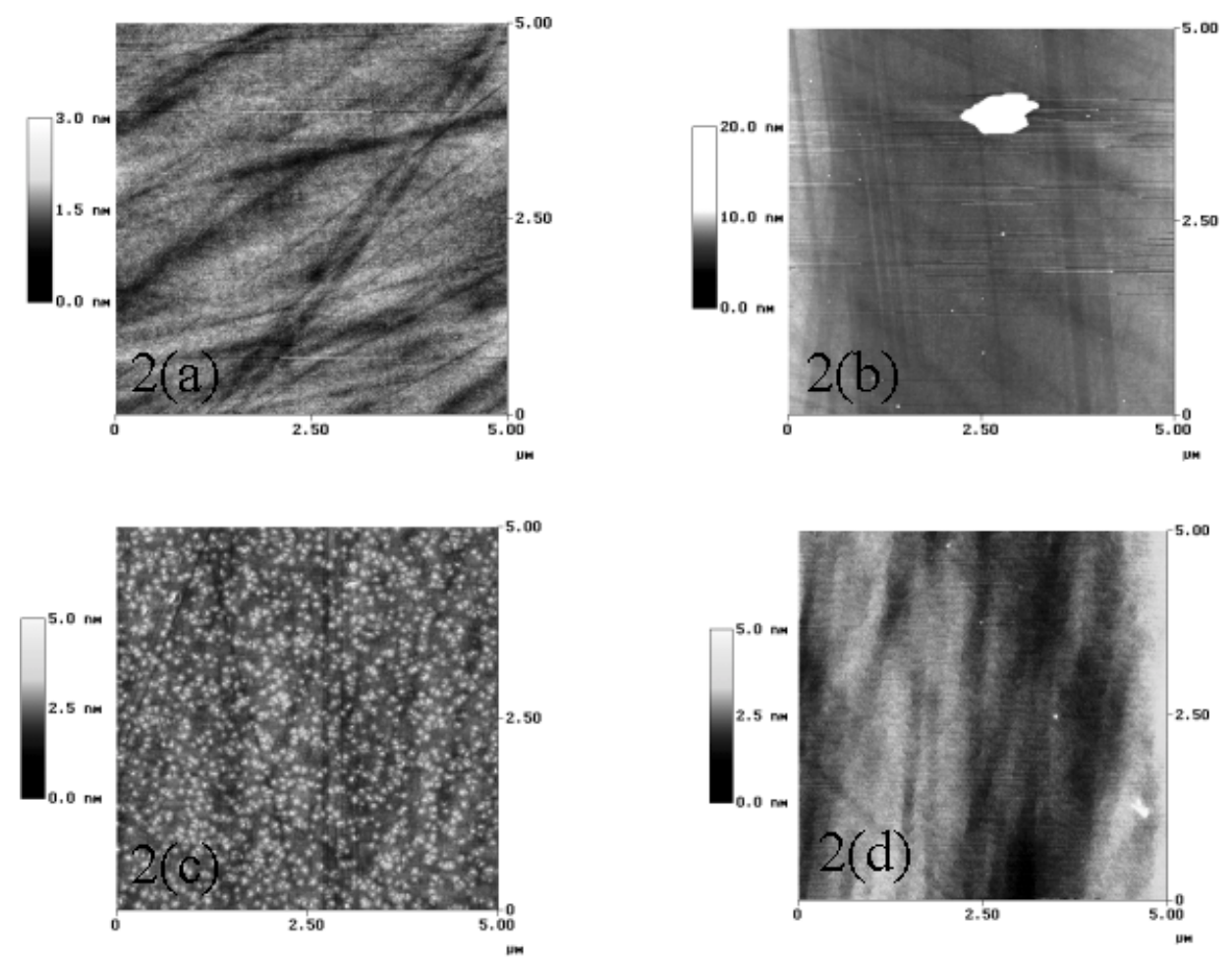

Figure 2. AFM images after annealing of sapphire for 30 minutes at (a) $1100^{\circ} \mathrm{C}$; (b) $1200{ }^{\circ} \mathrm{C}$; (c) $1300{ }^{\circ} \mathrm{C}$; and (d) $1380{ }^{\circ} \mathrm{C}$, respectively. 

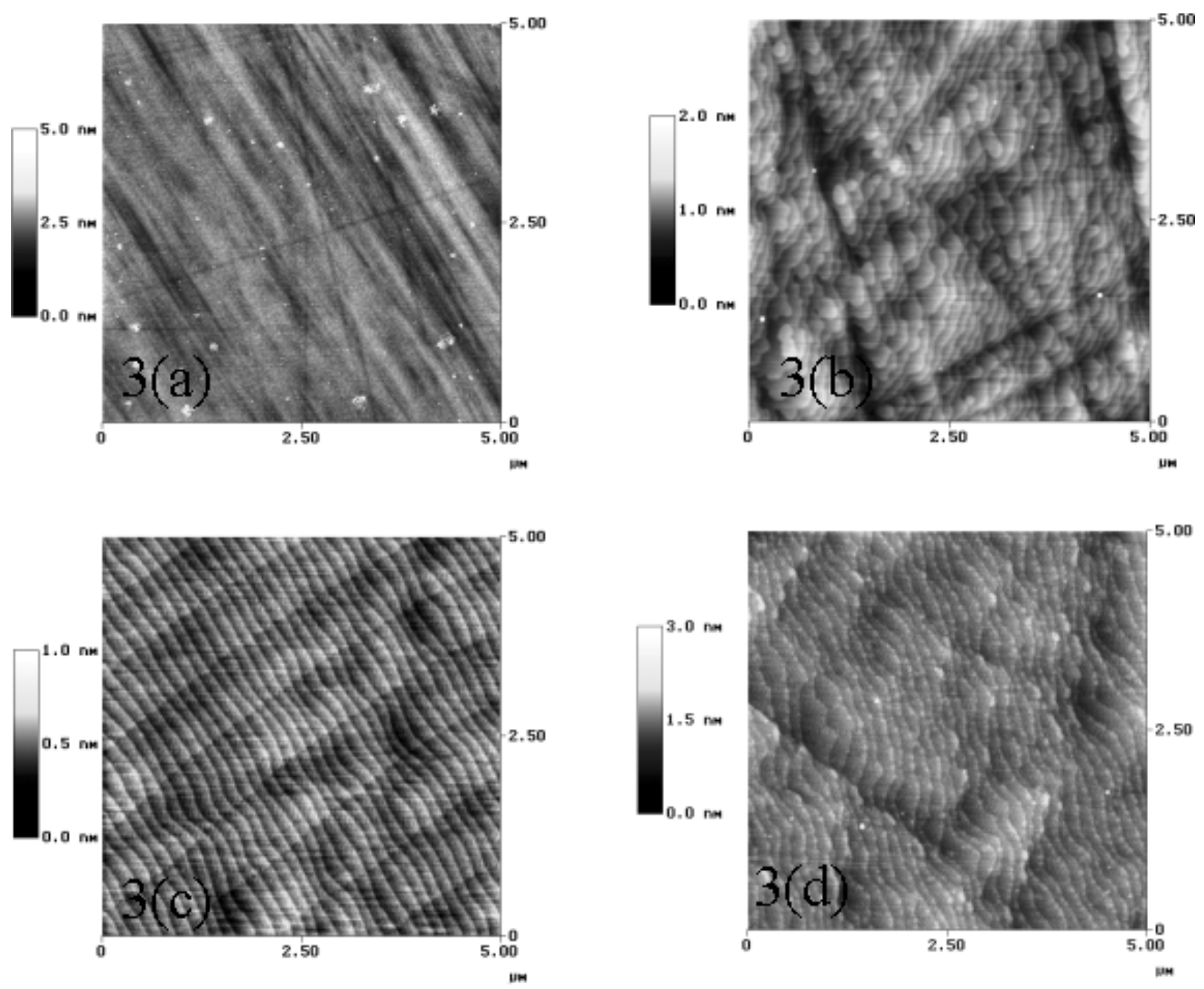

Figure 3. AFM images after annealing of sapphire for 1 hours at (a) $100{ }^{\circ} \mathrm{C}$; (b) $1300{ }^{\circ} \mathrm{C}$; (c) $1380{ }^{\circ} \mathrm{C}$; and for 3 hours at $1380{ }^{\circ} \mathrm{C}$ (d). 


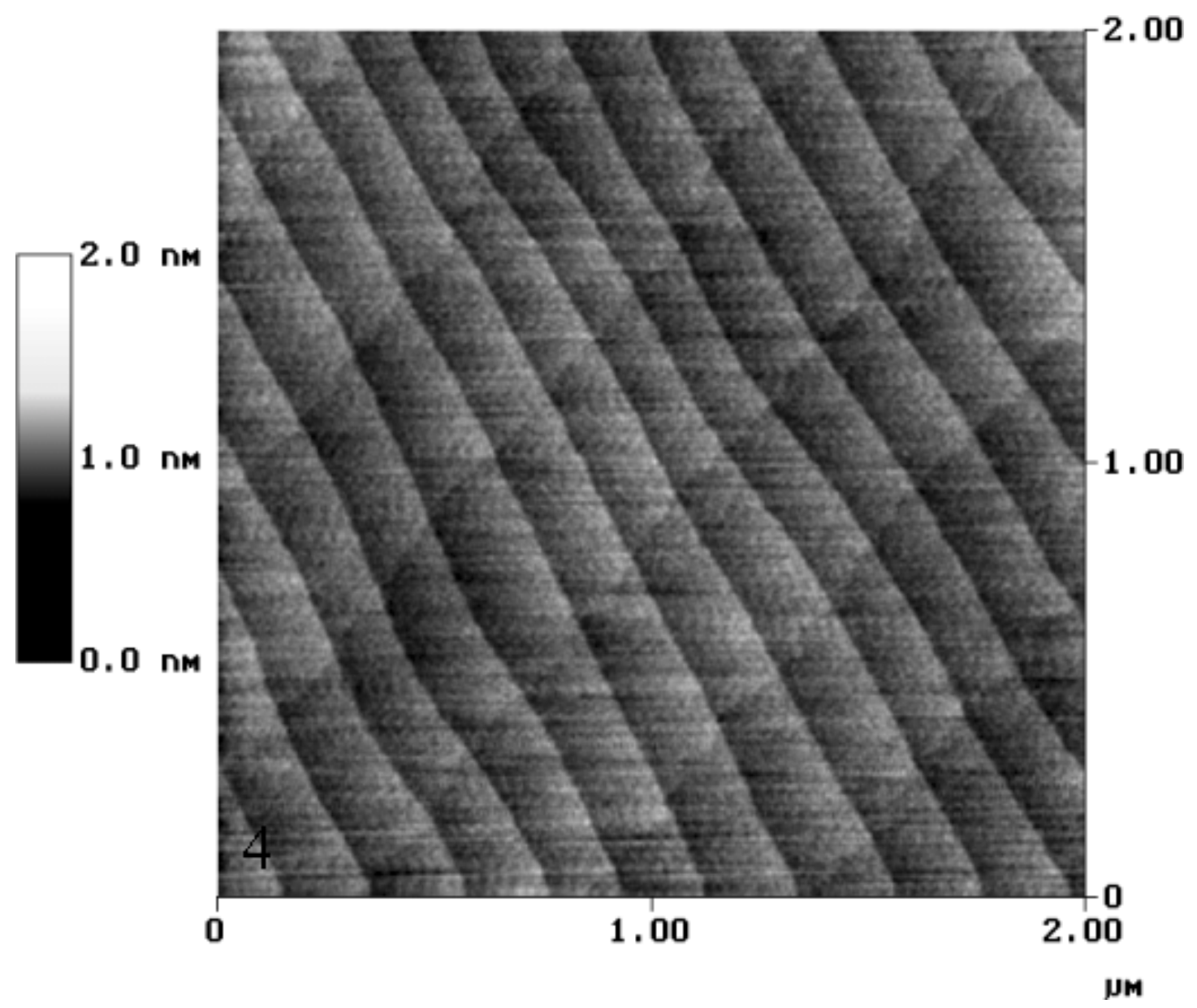

Figure 4. AFM image of sapphire annealed at $1380{ }^{\circ} \mathrm{C}$ for 1 hour showing terrace-like features with about 0.2 micrometer long terraces.

\section{TABLES}

Table 1. A list of X-ray rocking curves data in the samples.

\begin{tabular}{|l|l|l|l|l|l|l|}
\hline Sample & Substrate & MBE & $\begin{array}{l}\text { Thickness } \\
(\mu \mathrm{m})\end{array}$ & $\begin{array}{l}\text { X-ray[0 0 2] } \\
\text { arc second }\end{array}$ & $\begin{array}{l}\text { X-ray[1 0 4] } \\
\text { arc second }\end{array}$ & $\begin{array}{l}\text { X-ray[0 0 6] } \\
\text { arc second }\end{array}$ \\
\hline Sapphire substrate & Annealed sapphire & & & & 28 & 42 \\
\hline GaN SVT319 & $\begin{array}{l}\text { Un-annealed } \\
\text { sapphire }\end{array}$ & RF & 0.45 & 408 & 600 & \\
\hline GaN SVT389 & Annealed sapphire & RF & 0.98 & 69 & 252 & \\
\hline GaN R6385 & Annealed sapphire & NH3 & 0.54 & 60 & 132 & \\
\hline
\end{tabular}

